\title{
COMPARATIVE STUDY OF OFFSET TIME SCHEMES OVER OPTICAL BURST SWITCHING (OBS)
}

\author{
ABDUL SALAM A. YAYAH ${ }^{1}$, ABDUL SAMAD ISMAIL ${ }^{2}$, MOHAMMED. \\ A. AL-SHARGABI ${ }^{3} \&$ SEVIA M.IDRUS ${ }^{4}$
}

\begin{abstract}
The dramatic and continuous use of the Internet has increased the network traffic that is needed to be transferred through the Internet network. Optical Burst Switching (OBS) has met the requirements of such demands and is considered as a solution of the issues present in Internet networks. However, there are still some issues in OBS network have not been solved. Minimizing offset time delay is one of these concerns and a lot of research has been introduced in order to solve this issue through using various ways or schemes. In this paper, a description of these schemes and their advantages and disadvantages is presented.
\end{abstract}

Keywords: OBS; offset time

\begin{abstract}
Abstrak. Penggunaan internet yang meluas dan berterusana menyebabkan kenaikan trafik dalam talian. Teknik Optical Burst Switching (OBS) boleh dikatakan sebagai penyelesaian kepada masalah trafik di dalam rangkaian internet. Namun demikian, terdapat beberapa isu dalam rangkaian OBS. Salah satu isunya adalah untuk meminimakan offset masa tunda dan untuk mengatasi masalah ini, terdapat banyak penyelidikan dilakukan menggunakan berbagai cara dan teknik. Laporan ini menyediakan penerangan mengenai skema yang telah digunakan disamping menghuraikan mengenai kelebihan dan kekurangan skema yang telah sedia ada.
\end{abstract}

Kata kunci: OBS; offset time

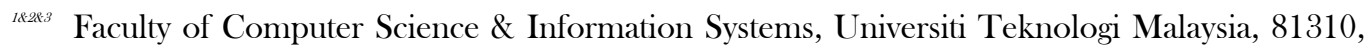
UTM Johor Bahru, Johor Darul Ta'azim, Malaysia

4 Photonic Techology Centre, Faculty of Electrical Engineering, Universiti Teknologi Malaysia, 81310, UTM Johor Bahru, Johor Darul Ta'azim, Malaysia

Corresponding author: amyabdulsalam2@live.utm.my 


\subsection{INTRODUCTION}

In recent years, a further and continuous research has been introduced on optical burst switching (OBS) since it combines the best characteristics of both Optical circuit switching (OCS) and Optical packet switching (OPS) such as minimizing the setup latency [1]. In OBS network, the data is transferred in bursts instead of packets and these bursts also vary in size. The packets are assembled into bursts at the ingress edge node and separated into packets again at the egress edge node. There are some issues in OBS network that are being studied. Reducing the end to end delay is one of the most important issues that represents the concern of many researchers studying OBS network [2].

This paper compares the existing offset time schemes and is organized into several sections. The next section, introduces Optical Burst Switching (OBS) network. Offset time and its role are presented in Section III which is the core section of this paper. Section IV provides a description of the existing offset time schemes. Finally, section V concludes the paper.

\subsection{OPTICAL BURST SWITCHING (OBS)}

OBS is a telecommunication technique that allows dynamic sub-wavelength switching of data. The wavelength resource is shared between different connections; where, the control signals or headers are sent separately ahead the data or packets (burst) in order to configure the switches along the burst's route [1]. Each burst is assigned a control packet (CP), which is delivered to a core switching node with some offset time prior to the burst payload. The offset time allows the control packet to be processed and the switch to be set up before the arrival of the burst to the intermediate nodes, so no electronic or optical buffering is necessary at the intermediate nodes. The duration of the burst is also specified through the CP, so the node knows when it may reconfigure its switch for the next arriving burst. Also, resources can be allocated in more efficient manner and a higher degree of statistical multiplexing [1, 3].

Since OBS was proposed to avoid the shortages of OCS and OPS, table 1 illustrates that OBS has combined the best characteristics of both of them. As a result, the characteristics such as high bandwidth utilization, low setup latency, and a voidance of optical buffering are included [1]. In OBS network architecture, there are two kinds of nodes as shown in Figure 1, which are edge and core nodes. The edge side consists of two nodes which are the ingress node (source) and egress node (destination). In the core node, optical bursts are switched or routed from a fiber link to another [2]. 
Table 1 The comparison between the three switching methods in the optical networks

\begin{tabular}{|c|c|c|c|}
\hline Characteristic & Circuit & Packet & Burst \\
\hline $\begin{array}{c}\text { Bandwidth } \\
\text { Utilization }\end{array}$ & low & high \\
\hline Setup Latency & high & low & low \\
\hline Optical Buffer & not required & required & not required \\
\hline Signaling Scheme & two ways & one way & one way \\
& out-of-band & in-band & out-of-band \\
\hline
\end{tabular}

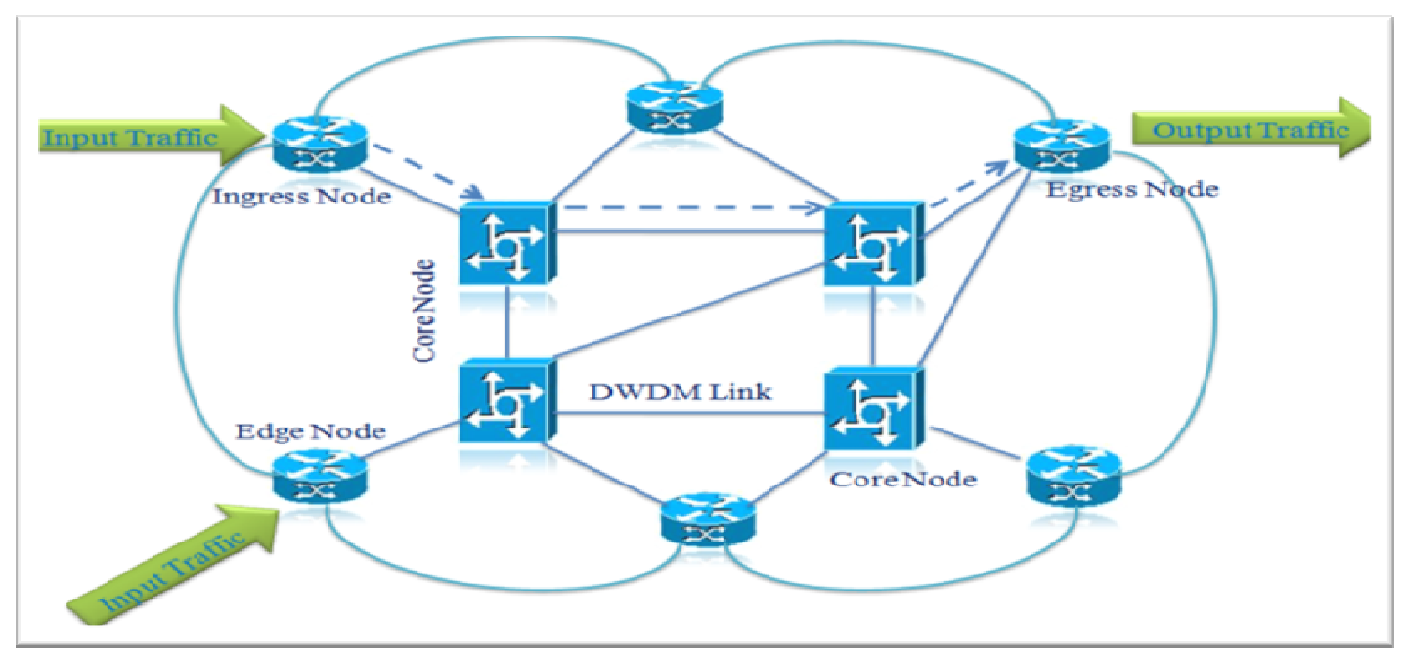

Figure 1 The OBS network architecture

An ingress node can receive different types of client networks such as IP, ATM, GbE, SONET or other networks. It has multiple functions which are initially assembling burst, scheduling the transmission, and setting up a basic offset time. The assembled burst consists of packets that are sent to for a specific destination. After burst assembly, the transmission is scheduled by using a scheduling or wavelength assignment algorithm. The bursts and their control packet are transmitted at prespecified times, where there is a value of an initial offset between these bursts and their control packet [2, 4]. Offset time and its schemes will be discussed in detail in next section. 
In a core node, signaling protocols and related forwarding and control functions are implemented, in which the switching of burst from input to output ports is also performed by the optical cross connect (OXC) [2].

The egress node is the receiver of the burst, where the burst is disassembled into packets by the burst disassembler. After disassembling the burst, packets are sent up to the higher network layer.

\subsection{OFFSET TIME}

For transmitting a burst through OBS, a burst header packet (BHP) is initiated and sent first. After a period of delay (offset time), the data burst is sent. Having an offset time in OBS is important to allow the nodes to configure the switches along the path [3]. In addition, it allows the control packet to reserve the resources (wavelength) at the core nodes in order to forward the burst. Reserving the wavelength is done by converting the BHP to an electronic signal and then to an optical signal again in each core node. BHP conversion is used in order to send the burst as an optical signal without OEO conversion along the path [7]. Figure 2 shows offset time scheme.

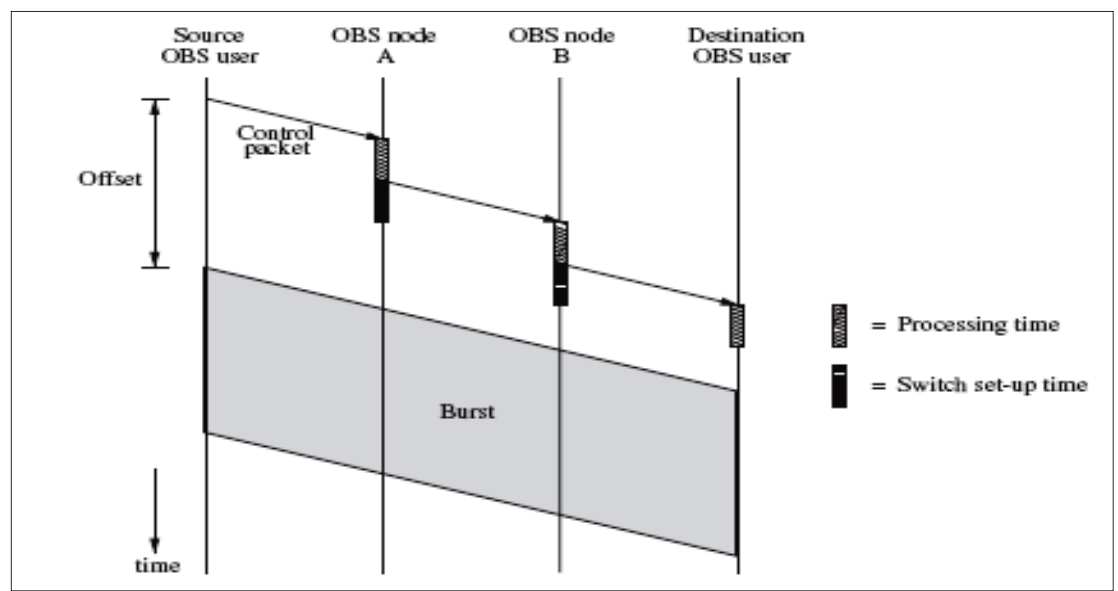

Figure 2 Offset time scheme

As a result of the configuration and reservation time taken at the core nodes, the offset time should be longer than the sum of BHP processing time at all nodes. In case of that offset time was shorter than processing time, the burst will arrive before the BHP and so it will be discarded. Thus, the effectiveness of any offset time scheme is measured through the burst loss probability. 


\subsection{OFFSET TIME SCHEMES}

In this section, a description of seven offset time schemes, which are fixed offsets, Adaptive offset time scheme, Using offset time for burst assembly, virtual fixed offset time, offset-based OBS QoS mechanism, load-adaptive offset time algorithm, and dynamic offset time windows mechanism, is presented.

\subsection{Fixed Offsets}

Fixed offset time scheme comes from OBS protocol Just-Enough-Time (JET), which is proposed by Qiao and Yoo (1999). In this protocol, offset time is fixed and equals the sum of the total processing time of all the intermediate OBS hops ,the switch fabric configuration time of the egress OBS node[1].

The number of hops from the ingress node to egress node is required to be known in order to estimate the offset time and such information is mostly provided by the edge OBS node. In fixed offset time scheme, the processing and switch configuration time at each OBS node are equal. However, these times may differ from node to node while having queuing delays in the control channel. Figure 3 shows the reservation process in fixed offset time scheme.

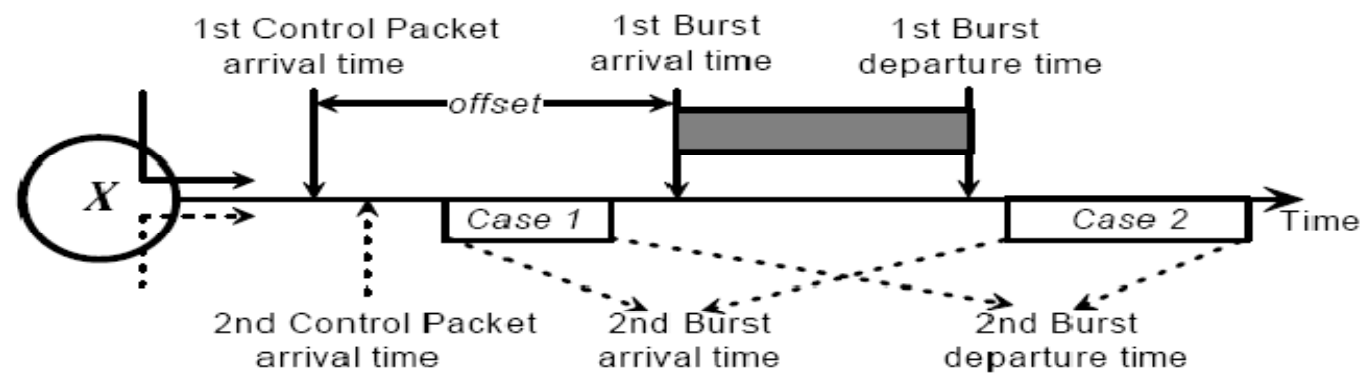

Figure 3 Fixed offset time

The disadvantage of this scheme is that having fixed offset time may give extra time for small bursts while they can be sent earlier without delay. On the other hand, big bursts will not have enough time in order to be sent. 


\subsection{Adaptive Offset Time Scheme}

In adaptive offset time scheme, extra offset time is assigned to bigger bursts in order to get a high isolation degree among bursts that have different sizes [5]. Also, an isolation degree of 1 can be achieved if the offset time differentiation equals the burst size. Hence, by assigning the extra offset time to bigger burst, the blocking probability is decreased and the overall good put of the network is increased. Figure 4 shows the offset time differentiation to avoid contention where $\mathrm{T} 1$ is the offset time of burst-I, T2 is the offset time for burst-j ( $\mathrm{Ti}_{\mathrm{i}}>\mathrm{Tj}$ ) and $\mathrm{Bj}$ is the duration of burst-j.

The disadvantage of the scheme is that longer delay and thus bigger loss penalty will occur as a result of the extra offset time. However, adaptive offset time scheme is more suitable to be used in the long distance network with large Real time traffic and so the offset time will be negligible compared to the transmission delay.

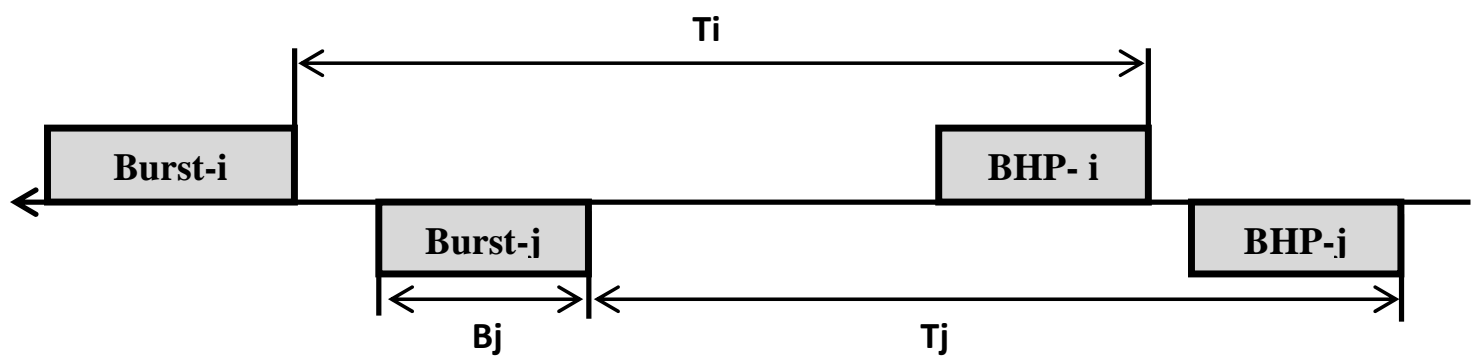

Figure 4 The channel using adaptive offset time

\subsection{Adopting The Jacobson/Karels Algorithm for Offset Time Scheme}

In this approach, the offset time is reduced through burst assembly when burst assembly period is shorter than the offset time by forwarding the control packet that contains estimation for the burst length before the burst assembly period ends [6]. This scheme is effective since it does not cause extra offset time delay and the transmission of the burst is achieved more quickly than the conventional method. However, in order to send the CP before the burst assembly period ends, the burst length should be estimated and inserted into the header of the $\mathrm{CP}$ by using Jacobson/Karels algorithm to calculate the retransmission time in transmission control protocol (TCP) [11]. The difference between this scheme and the other scheme proposed that it solves the problem of the delay by eliminating the delay 
happens during the assembly period instead of solving the delay problem through transmission time.

\subsection{Virtual Fixed Offset Time (VFO)}

It is difficult to have all bursts with the same offset time due to the processing delay of the $\mathrm{CP}$ at all nodes from ingress to the egress [7]. To solve the problem of the processing delay which is different from one to another, the Virtual fixed offset time (VFO) was proposed. Unlike other OBS reservation algorithms, VFO processes bursts according to burst arrival time instead of the $\mathrm{CP}$ arrival time. Although, VFO is similar to fixed time approach since the burst has a constant offset time, it still uses variable offset time. After sorting the CPs according to their burst arrival time, the burst with the earliest arrival time is scheduled. However, to guarantee that no other bursts will arrive prior to the earliest burst scheduled, fiber delay lines (FDLs) are used to increase burst offset time at each node in order to delay bursts. The architecture of VFO at each OBS node is illustrated in figure 5.a while figure 5.b shows how the offset time of a control packet changes in VFO as it goes through different phases. Even though, VFO scheme improves the transmission delay in general, it also add an offset time delay to bigger bursts and send directly small bursts. This operation creates the problem of unfairness among bursts by increasing the delay time for bigger bursts even by intentionally delaying the big bursts in each node by using FDLs. Moreover, the use of FDLs is considered to be expensive to be used.

\subsection{Offset-Based OBS QOS Mechanism}

Qaio and Yoo, (2000) proposed a novel scheme which is the offset-based OBS QoS mechanism. In this scheme, the classes of traffic are isolated to give the higher priority classes a greater chance to allocate the resources than the lower priority classes. In the offset-based OBS QoS mechanism, an additional offset time is added between the control packet and data burst based on their priority which increases the reservation possibility. Since the higher priority bursts segment the data wavelength, the lower priority bursts tend to reserve only the gaps left by the higher priority bursts as shown in figure 6 [8]. 


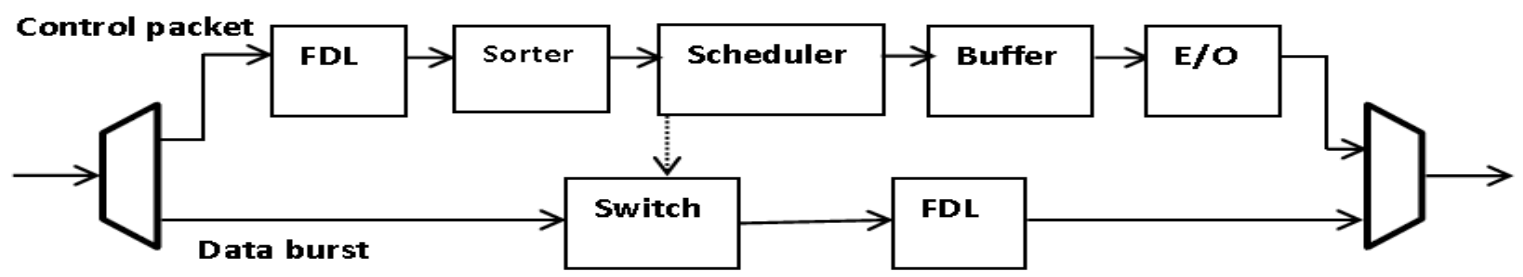

Figure 5a Core node VFO

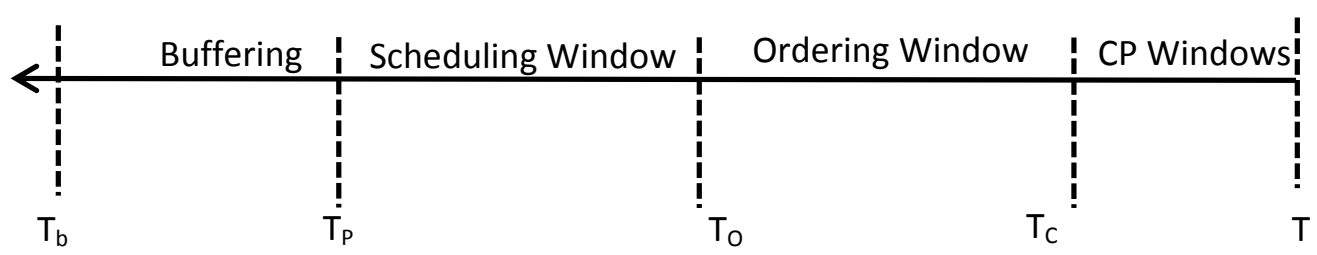

Figure 5b The phases a control packet will go through in VFO

Providing higher reservation probability to the higher priority bursts causes the higher priority burst to wait for a long time before being served. On the contrary, the short low priority bursts have a lower burst loss probability than the longer low priority bursts, as they have a higher probability to fit into the gaps.

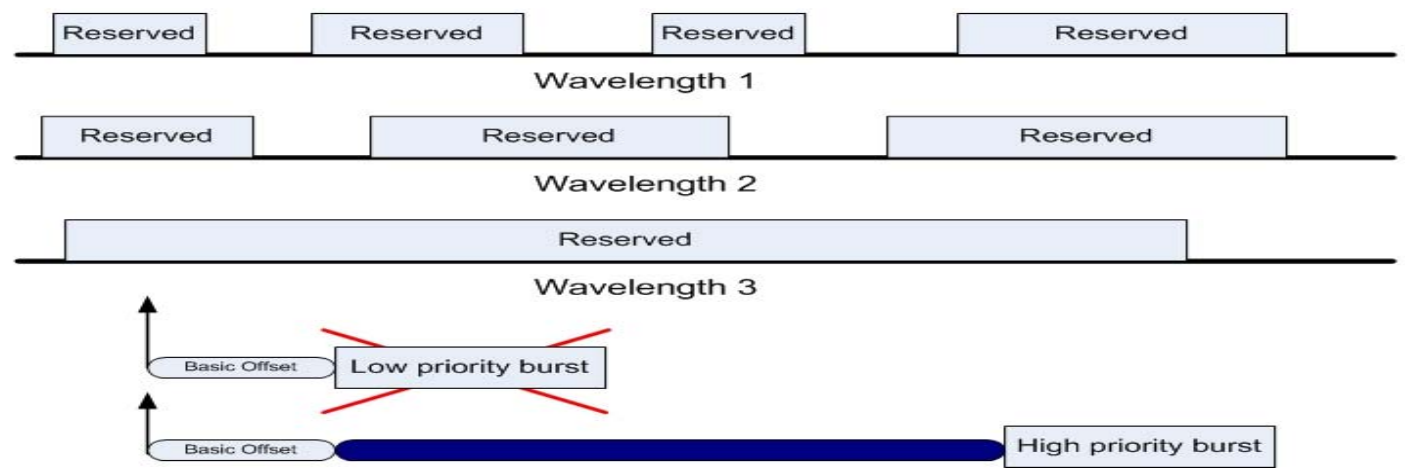

Figure 6 The offset-based OBS QOS mechanism 


\subsection{Load-Adaptive Offset Time Algorithm}

Mart'inez, et al, (2007) proposed a method called Load-adaptive Offset Time (LOT). In LOT, the BCP variable sojourn time for the offset time calculation is taken into account. LOT has avoided previous issues such as the bottleneck and network load. The aim of LOT was to propose a technique for providing an offset time that is long enough in order to minimize burst blocking, but small enough in order not to increase end to end delay. The calculation process of the offset time in LOT is done adaptively to the Switch Control Packet (SCU) load along the path form source to destination. Estimations that are very close to the actual sojourn time experienced by the BCPs are produced by LOT. These estimations are produced for both BCP service time distributions assumed which are constant service time and Gaussian service time. For LOT to be applied on OBS network, the SCUs do not work at the peak rate [9].

\subsection{Dynamic Offset Windows Mechanism}

When two sources try to schedule a burst at a near time, a conflict may occur. This could happen due to the delay between the scheduling of a burst made by a source and the update of the information by other sources. In Dynamic offset windows mechanism, the closest node to the shared link between the sources defines an interval of time for every source [10]. These scheduling time intervals (offset windows) are given dynamically. The source that has the farthest init window offset time has the greatest minimum delay but without contending with other sources while the other sources take advantage of Wavelength Occupation Vector (W.O.V) knowledge to avoid contention. This method can be used to provide Quality of Service (QoS) policies since it treats sources differently. As a disadvantage, a range of delays are achieved in order to satisfy the latency requirements.

\subsection{CONGLUSION}

In this paper, a survey of several offset time scheme over OBS have been introduced. The advantages and disadvantages of the previous schemes vary according to each scheme and methods presented. In general, this paper discusses two main issues, which are optical networks and existing offset time schemes. OBS network which is the field of this research has combined the advantages of both OCS and OPS. After that, a review of the existing offset time schemes was included in order to understand and present the multiple techniques used to solve the delay 
or provide QoS provisioning. However, the presented schemes did not meet real time traffic delay requirements since it is not a concern in these schemes

\section{FUTURE WORK}

The researchers will follow up to propose a new offset time scheme that guarantees the delay in particular of real time traffic over OBS network.

\section{REFERENGES}

[1] Qiao, C., and Yoo, M. 1999. Optical Burst Switching (OBS) - A New Paradigm for an Optical Internet. Journal High Speed Networks. 8: 69-84.

[2] Papdimitriou, G., Papazoglou, C., \&Pomportsis, A. 2007. Optical Switching. New Jersey: John Wiley \& Sons, Inc.

[3] Battestilli, T., and Perros, H. 2003. An Introduction to Optical Burst Switching. Communications Magazine, IEEE. 41(8): S10-S15.

[4] VOKKARANE;, J. P. J. V. M. 2005. Optical Burst Switching Network. B. Mukherjee,. United States of America, Springer Science + Business Media.

[5] X. Cao, et al., 2008. An Adaptive Offset Time Scheme in OBS Network. 7th International Conference on the Optical Internet, COIN 2008. Art. no. 4773374.

[6] T. Mikoshi and T. Takenaka, 2008. Improvement of Burst Transmission Delay Using Offset Time for Burst Assembly in Optical Burst Switching. 7th Asia-Pacific Symposium on Information and Telecommunication Technologies, APSITT. Art. no. 4653532. 13-18.

[7] Li, J., Qiao, C., Xu, J., Xu, D., 2007. Maximizing Throughput for Optical Burst Switching Networks. IEEE/ACM Transactions on Networking. 15 (5): 1163-1176.

[8] M Yoo, et al., 2000. Qos Performance of Optical Burst Switching in IP Over WDM Networks. IEEE JSAC. 18( 10): 2062-71.

[9] Martinez, et al., 2007. Optimizing Offset Times in Optical Burst Switching Networks with Variable Burst Control Packets Sojourn Times. Optical Switching and Networking. 4(3-4): 189-199.

[10] Agusti, A., Cervelló-Pastor, C. A. New Contention Less Dynamic Routing Protocol for Obs Using Wavelength Occupation Knowledge. Proceedings of the Mediterranean Electrotechnical Conference - MELECON 2. 519-522.

[11] Peterson, Larry L. 1996. Computer Networks: A systems Approach. Morgan Kaufmann. 